\title{
ENTREVISTA COM A PROF" DULCE REGINA ROQUETTE LOURES
}

Neste número, Paidéia optou por entrevistar um diretor de escola pública que, como os estudos de campo sempre mostram, é peça fundamental tanto para o bom quanto para o mau funcionamento de uma escola. A Profa. Dulce teve uma experiência de 28 anos no magistério, aposentando-se em Setembro de 1992 como diretora da Escola Estadual Djanira Velho, em Ribeiräo Preto-SP. Foi inicialmente professora de escola nural durante 8 anos, secretéria de escola por 3 anos $e$ o restante do tempo foi diretora. Atualmente exerce a funçăo de coordenadora pedagógica na rede privada de ensino.

\section{Paidéia - Como fol sua formação escolar ?}

- Prof Dulce - Primário no grupo escolar Joaquim Antonio Pereira em Fernandópolis. Nos ajudamos a construir essa escola, sou quase fundadora da escola. Ginásio e o Curso Normal, naquele tempo chamava Curso Normal, foi feito no Instituto de Educação de Fernandópolis também. Tudo escola pública. seu tempo?

P - E ạ́, a escola pública de hoje é pior do que a escola pública do

D - E muito pior, eu sinto assim que eu não tenho nenhum curso de Pós-graduaçāo, não tenho nada além do que todo mundo tem, que $\epsilon$ o Curso de Pedagogia e o Curso Normal, mas que eu tenho uma visão muito maior do que as demais pessoas! Quando a gente está em uma reuniāo, eu percebo a grande diferença que existe. Eu acho que é a formaçāo mesmo que a gente teve; naquela época estudava-se latim/francếs/inglês/história geral/história brasileira/geografia geral/geografia do Brasil. Entāo, eu acho que a gente teve uma noçāo de tudo, o que falta agora.

\section{P - Por que piorou tanto a escola pública ?}

D - Eu acho que houve uma perda da qualidade com a democratização do ensino. Não houve um preparo para receber esse público todo; então, começou a sobrar, sobrar em que termos? Aluno fora da sala de aula, porque a rede não conseguia responder ao aumento da demanda, depois uma formação rápida, correndo... correndo, tudo visto por cima, levando ao despreparo desses alunos que depois seriam professores e educadores e assim por diante. Então, houve aí uma falta de organização. 
bastante?

P - Quer dizer que você acha que o nível dos professores caiu

D - Muito... muito... muito... Posso até contar uma passagem aqui.: nós tivemos uma Professora de História, e isso marcou muito a minha vida. Ela nunca entrou em sala de aula com um livro para ser seguido, ela sempre começava a história com uma verdadeira estória, deixava sempre um ponto de interrogação, uma reflexão para o dia seguinte. Hoje não, hoje o professor entra com o livro e segue aquele livro, somente aquele livro. Em casa não tem tempo de estudar, não tem tempo de preparar e ainda tem o maldito Livro do professor, que eu acho que é o desastre de toda a educação, não só pública. $O$ professor fica restrito àquelas perguntinhas, que já vêm prontas.

P - Você tem dados a respeito do salário dos professores hoje no Estado de São Paulo?

D - Não tenho dado preciso, não, mas em média o Professor I, que atende o aluno da 1a. a 4a. série, em Jornada Única de 40 horas semanais recebe, mais ou menos, Cr\$3.100.000,00 por mês; Professor III, na mesma jornada, Cr \$3.800.000,00; Diretor de escola, 40 horas também, Cr \$5.200.000,00.

P - Falando agora do Diretor de escola. A gente sabe que pelo Brasil, o Diretor acaba sendo um cargo basicamente político, geralmente ele é indicado. O Estado de São Paulo tem uma certa tradição de concurso para Diretor. Como você vê está experiência? Como você vê o papel do Diretor? Diretor é aquele que só controla papéis, ou ele é mais do que isso?

D - Ele não pode ser só controlador de papéis, para isso existe o secretário de escola. Muitos, com a deficiência da formação, jogam a culpa no cargo, alegam que só tem que cuidar de papéis. Não é uma verdade. O Diretor tem o papel de "integrador" de todas as açōes, cabe a ele a integração entre a comunidade/alunos/professores/ e a administração da escola. Agora se ele fica preso só em papéis, porque a Secretaria de Educação (os orgãos centrais) cada vez exige mais informaçōes, ele nāo exerce sua função. Para isso, ele tem todo um grupo de apoio, é a Secretaria da escola. Ele deve é usar dessa documentação para integrar as ações da escola, não fazer disso o objetivo final de todo o seu trabalho.

P - Se o Diretor de escola tem, como você disse, este papel de integrador, você não acha então que, em virtude desse caráter de articulador com a comunidade, o cargo de Diretor deveria ser preenchido por eleição? 
D - Al eu tenho um pouco de dúvidas quanto à eleição, porque passa a ser um orgão só político, precisaria de eleição e também uma sondagem para ver a liderança daquela pessoa e não a indicação somente política. A gente percebe que em lugares onde ocorreu eleição houve um grande transtorno, houve até guerra dentro da escola. Eu näo teria medo de uma eleiçāo, porque eu sempre procurei exercer a função que realmente está prevista, não só na legislação como na integra da função. Mas eu tenho um pouquinho de medo da eleição de um modo geral, porque passa a ser uma função política só.

\section{P - Como voce vê a participagăo da comunidade na escola?}

D - Vejo com ótimos olhos, e tenho uma experiência muito feliz. Quando eu assumi essa escola da qual me aposentei , a comunidade tinha aversão pela escola. Levar a comunidade para a escola foi a minha meta e com isso eu consegui muita coisa, consegui até mesmo uma APM que näo so trabalhasse para arrecadar fundos, mas que reivindicasse um curriculo mais rico, fazendo até mesmo pressōes junto ao Secretário da Educação. E a Escola Padrāo, implantada em 1993 no Djanira Velho, s6 saiu graças ao trabalho da comunidade.

\section{P - Quais săo os recursos que a escola tem à sua disposição?}

D - A comunidade, esse é o grande recurso da escola, porque os recursos financeiros sāo raros e mal distribuídos. Um exemplo, eles às vezes chegam com a destinaçāo para comprar 2 mil cadernos, mas a escola nāo está precisando de cadernos. Então recursos são poucos, agora se a comunidade estiver junto com a direção, aí a gente consegue muita coisa mesmo e dá para fazer um trabalho muito bom, todo mundo trabalha em conjunto.

P - Com a criagão no Estado de São Paulo dos Conselhos de escola, você não acha que o papel da APM foi esvaziado, porque as vezes a gente sente algumas Escolas públicas com mais recursos, que a APM acaba sendo um certo instrumento quase que de privatizacão da escola, na medida em que ela passa a contribuir de forma significativa com os recursos e acaba às vezes se transformando em instrumento de exclusāo dos alunos mais carentes na medida em que são cobradas taxas de APM elevadas ( apesar da legislação proibir sua compulsoriedade) Você acha que existe este risco?

D - Na realidade existe, agora isto daí é por causa do controle do Estado. Tem escola que cobra muito, mas não é só. A questão é do nível de participação da comunidade. Onde a gente vê um todo, a APM junto com o conselho e a Direção da escola, com o corpo docente, discente, consegue-se trabalhar harmoniosamente com um objetivo s6 e a "escola cresce em todos os 
sentidos". Agora onde a APM é só um orgāo financeiro, af houve o esvaziamento mesmo, porque criou-se até um problema, a guerra entre a APM e o Conselho de escola.

P - Dentro da realidade do Estado de São Paulo, no caso de um professor que năo exerce condgnamente sua profissåo ou de um Diretor que absolutamente nảo está preocupado com a sua escola, existe condiçōes de tirar esse professor ou Diretor desta escola? A comunidade tem condiçōes de fazer isso na estrutura legal atual ?

D - Al recai na formação novamente, teria condições se a formação do profissional fosse melhor, porque ele ao perceber que a comunidade não está satisfeita, ou tiraria o time de campo ou ele procuraria se reformular, se refazer nas açōes. Mas atualmente da forma que está, nảo tem condiçōes, principalmente quando o profissional é concursado.

\section{P - Como você avalia o CICLO BÁSICO?}

D - Eu vejo o ciclo básico como uma oportunidade maior da criança se alfabetizar, tem mais tempo de aula, há 2 anos para se trabalhar em amplo sentido a alfabetização. Diminui um pouco a evasão, porque o aluno tem essa oportunidade. Agora ele precisa ser repensado. Não basta a criança ficar 2 anos na alfabetização, é preciso rever também o modo que se alfabetiza, não adianta nada colocar a criança novamente para trabalhar com aquela cartilha, com 0 mesmo conteúdo que ela viu, da mesma forma que ela viu no ano anterior. Isso só vai agravar o problema, não vai resolver. Agora, se for trabalhado seriamente com os professores, o que raramente acontece, seria a solução.

P - As estatísticas mais recentes, principalmente os estudos de Claúdio de Moura Castro e Sergio Costa Ribeiro, alertam que o problema da escola páblica não é a evasão e sim a repetência; voct concorda com essa afirmaçāo?

D - Concordo em parte, porque a evasão também é muito grande, não tanto de 1a. à 4a. série, mas no período noturno a evasão é muito grande, precisa ser trabalhada seriamente. Agora a repetência é um caso sério mesmo, mas eu acho que a repetência ocorre também pela formação do professor. 0 professor não consegue fazer um trabalho individualizado, atender necessidades daquela criança, conhecer a criança a fundo, ele näo consegue. Também passa por uma coisa muito séria e que ninguém toca, o número de alunos por classe. As classes não poderiam ter mais que 20/25 alunos, no entanto a gente tem classe com 40/45, $2^{\circ}$ grau chega a ter 50 . E impossível, mesmo para o professor bem 
formado.. Se o Estado quissesse resolver o problema, teria que diminuir o número de alunos por classe e exigir do professor um trabalho mais individualizado.

P - E a experiéncla da jornada única aqui no Estado de São Paulo, onde os alunos do CB ficavam 6 horas na escola, como voce avalia ? E a passagem desse processo para a Escola Padrão?

D - A jornada única eu acho uma grande saída para o problema, desde que sejam levadas a sério as horas de estudo, com um acompanhamento efetivo do aluno pelos professores. $O$ objetivo da Escola Padrão é examente esse, é a garantia de um horário que o professor vai ter para estudar, para sentar, preparar as suas aulas. Enquanto a experiência se resume a um numero restrito de escolas, está funcionando muito bem isto, mas depois que passar para a rede toda, não sei como vai ficar. Acho que é uma experiência, a gente tem que participar dela, não sou a favor de ficar fora não. Temos que participar efetivamente, questionando os pontos falhos, tentanto mudar o que está errado, tem coisa'errada, há tarefas a serem executadas. Devemos começar a ver a escola de uma forma diferente mesmo. Mas precisa ver se vai haver continuidade também.

P - Não será a Escola Padrāo uma exceção ? Será que no fundo não estamos criando algumas Escolas vitrine, que quando voce quer chamar a imprensa você mostra! Como na verdade os recursos globais para a educaçáo foram reduzidos no governo Fleury, a pergunta que fica é: se você manda mais verbas para algumas escolas, tudo indica que as outras ficaráo mais desamparadas.

D - E, além disto eu percebo que houve também um pouquinho de lavagem cerebral sobre quem está dirigindo as escolas padrão, que não consegue perceber as falhas. Isso é muito grave, a gente não pode enxergar a escola padrão, como uma coisa que só vai dar certo, nós temos que prever também os fracassos.

P - Hoje no Brasil há várias tentativas de aumentar o tempo de permanência do aluno na escola visando o tempo intezral. Voce acha que o unico caminho para resolver os problemas educacionals do país é a escola de tempo integral ?

D - Eu acho que não é só esse. Em primeiro lugar precisaria estruturar, dar condições para a família fazer a opção. Agora, entre a criança o dia todo na escola, ou o dia todo na rua, eu prefiro a escola. Contudo não pode ser do jeito que está sendo feito; escola é hospital, é refeitório. Teria que ser escola - escola. $O$ período integral, teria que ser reformulado de forma a atender as crianças nas necessidades de brincar, de criar, ler, ver televisão, questionar a televisão. Trabalhar a criancice dela, o que acontece acaba sendo uma coisa massacrante, o dia inteiro lá, fazendo coisas que não lhe interessam, que não vão

Paidéia, FFCLRP - USP, Rib. Preto, 4, Fev/Jul, 1993. 
desenvolver nada nela, faz s6́ o que os outros adultos querem. Assim, acho que vai frustrar muito mais e matar o espírito crítico.

P - Com 4 horas de aula por dia, você daria conta de dar os fundamentos do $1^{2}$ grau em uma escola bem estruturada?

D - Eu fiz uma escola de 4 horas e aprendi muito mais do que estes que estão por 6 horas.

P - Agora que você esta passando por uma experiência na rede privada, que diferenga vocé vê entre a escola páblica e a escola privada?

D - Alguns pontos são bem diferentes; por exemplo, eu sinto que a escola pública dá muito mais autonomia. Eu exerço a função na escola privada de coordenador pedagógico, mas acabo exercendo também a de Diretor, porque o Diretor está mais distante, tem várias unidades para cuidar, a gente acaba respondendo também. Agora a grande diferença é a autonomia, quem trabalha na escola pública tem muito mais autonomia, consegue colocar o seu ponto de vista sim, e consegue trabalhar com mais liberdade. $O$ ponto positivo da escola privada é o controle de qualidade. $\mathrm{Na}$ escola privada é tudo controladinho, se existe um determinado assunto para ser abordado, esse assunto vai ser cobrado do professor, existe um registro e esse controle $\epsilon$ feito quinzenalmente pelo Coordenador pedagógico. Assim, eu vejo que a proposta da escola pública é aplicada na escola privada com êxito. Todo aquele conteúdo maravilhoso que há nas propostas curriculares desenvolvidas para a escola pública e que o professor nem chega a conhecer, é aplicado na escola particular com toda aquela infra-estrutura que precisa. Na escola pública, o professor é muito mais livre, só que não existe controle de qualidade. Ninguém cobra, a coisa é solta, está faltando uma cobrança, um retorno, que eu acho que poderia ser feito pelos pais. Professor do meu filho precisa trabalhar, meu filho não viu isso, nāo viu aquilo, não viu aquilo outro. Isso não é feito por ninguém nem pelo Diretor, nem pelo Supervisor, nem pelo Delegado de Ensino, nem pela Secretaria e nem pela Comunidade. Isso fica muito solto.

P - Como o pai também recebeu uma educação deficiente, talvez ele se sinta incapacitado para cobrar o conterido. $O$ que a gente sente, é que o pai quer a escola para o filho, mas ao mesmo tempo ele năo sabe como cobrar qualidade. No caso da escola privada, existe a mensalidade, fica claro para o pai que ele sustenta a escola. Na escola pública esta consciência é mais difusa, ademais a impressão que se tem é que as escolas buscam barrar esta participação .

D - Existe bloqueio sim, muitas vezes não se dá oportunidade dos pais se aproximarem do professor e da escola. Na escola particular, o pai cobra porque paga, mas também não sabe cobrar. Uma coisa que eu acho muito séria na escola particular é aquele enfeite do pavão, enxerta um monte de coisa (informática/natação/judô) que no final pouca coisa acrescenta para a educação da criança. Os pais precisam ficar alerta nesse sentido. 
P - Agora vamos falar dos "caras pintadas".Eles vieram para ficar? Como é a participaçäo política do aluno?

D - Eu espero que sim, eu tenho grande esperança nessa juventude. Contudo há ainda muito a se fazer. A minha juventude foi muito mais atuante que as das minhas filhas. Agora para isso precisa estar atento atualizado, ler jornal, que é um hábito que não é muito usado, preferem a revista Veja, que é um resumo de opiniōes já trabalhadas, a gente engole aquilo que o escritor escreveu. Eu tive um professor que dizia, a gente nāo pode ler um jornal sర, tem que ler 3 ou 4 por dia. A participação política e muito importante, eu espero que eles tenham, e vou fazer tudo para que os alunos que passem pela minha mão, estejam prontos a participar e participem.

P - Como fica essa situagáo na escola pública, há assinaturas de jornais, revistas? Como estảo os gremios das escolas páblicas?

D - Aí eu posso falar com tranquilidade, na escola que dirigi deixei a assinatura de um jornal local e de 3 revistas. Ficam na biblioteca para quem quiser consultar. Agora o grêmio existe e funciona, ele participaram das passeatas, eu fui de sala em sala e propus que eles fossem. Acho que a participaçāo deles é muito importante, agora todo mundo tem essa oportunidade. Eles precisam lutar por isso, não pode deixar fechar a porta não.

P - Para cerminar a nossa entrevista, a pergunta clássica,o que precisa ser feito para melhorar a escola pública ? Nós temos um professor que sofreu uma má formação, os salários sảo vergonhosos ( um professor da rede estadual ganha hoje 1/5 do que ganhava $\mathrm{em} 1964$ ), os diretores se apegam a tarefas burocraticas, a cobrança dos pais é pequena. Por onde é a saída ?

D - Um ponto que eu acho que precisa é acabar com o Livro do Professor. Isso obrigaria o professor a procurar outras fontes. Ele tem que ter a oportunidade de se reunir, estudar, já que a escola não deu a formação, a profissão vai dar. A reciclagem é uma coisa muito boa, muito válida e precisa existir.

P - Aproveitando, no que toca à reciclagem, quando a gente avalia as entrevistas dos professores, ela aparece como uma lembrança muito vaga, será que não é preciso repensar essa reciclagem ?

D - Eu acho que a reciclagem não pode ser só nas férias, só um mês de reciclagem, tem que ser sempre. $O$ professor tem que sentir vontade de se reciclar. Eu aprendi muito na reciclagem quando eu lecionava naquela escolinha rural, eu tenho muita saudade. Existia um órgão na Delegacia de Ensino que chamava Serop e a gente assistia, todas as tardes, aulas lá, só que era sem ganhar. Naquele tempo podia, agora a coisa ficou muito séria. Agora, a gente vai quando é estimulado, se a gente vê que ninguém olhou um trabalho melhor que a gente fez, a gente não vai ter vontade de continuar fazendo. E deve haver cobrança. 


\section{P - Quem deve cobrar?}

D - O Diretor, Supervisor de Ensino, Delegado de Ensino e os próprios pais. Elogiar quando for necessário, quando for preciso, quando existir a oportunidade de elogiar. Por outro lado, o pai tem todo o direito de criticar quando o professor falta demais, não cumpre com o calendário, com tudo que foi planejado. Os pais devem conhecer aquilo que foi planejado.

P - A gente fala aqui muito em cobranç e a pergunta que eu faço é a seguinte : Quem cobra o Diretor, o Delegado? As delegacias de ensino, para que servem?

D - Quem cobra o Diretor teria que ser o Supervisor. O Supervisor foi uma figura apagada na reforma do Ensino, porque ele passou a cuidar da escola particular, do reconhecimento da escola e a parte pedagógica ficou para trás. Criaram alguns orgãos de apoio pedagógico, mas que não têm competência para cobrar. Delegacia teria que ser um orgâo de apoio pedagógico mas passa a ser um orgāo so administrativo. Cobra do Delegado aquele político que o colocou. Was o Diretor também, ele é pouco cobrado. Por não ser cobrado ele é desestimulado. Se ele faz uma coisa boa, fica por isso mesmo, se ele faz coisa errodu tainbem fica por isso mesmo. Então ele passa a fazer um "arroz com feijāot st, e não é por aí.

P - Agora se preencher um papel errado, não fica por isso mesmo. Talvez por isso que ele acabe burocratisando.

D - Exatamente, daf volta toda a papelada, atrasando o recebimento da ínfima verba e de tudo mais.

\section{leitores?}

P - Profa. Dulce, gostaria de dar um recado final aos nossos

D - Bom, eu estou falando para a USP, que forma professores. Gostaria que a USP se preocupasse muito com a formação desses professores, apesar de serem poucos os professores que saem da USP. Ela acaba formando pesquisadores e, muitas vezes, professores que não vão para a rede pública. Isso é muito sério, precisaria haver mais estímulo da USP, para que os docentes que forma, fossem para a rede pública, para salvar essa rede. $O$ conteúdo que está aí é muito bom, muito bom mesmo, profundo e eu percebo que a saída é aplicar o que está aí, não precisa mais nada... nada... Agora a formaçāo do professor também caiu muito. Nós só recebemos professores de escolas particulares, cuja formação deixa muito a desejar. Eu vejo assim, às vezes tem professor com boa vontade mas ele não consegue alcançar o conteudo da proposta. E a gente percebe que, na USP, tem gente de boa cabeça que não vai para a escola pública,que isto é rechaçado pela formação.

P - Pror Dulce, muito obrigado pela sua colaboração. 